\title{
PROSES BONGKAR MUATAN CURAH CAIR DARI KAPAL MT.SUNRISE HOPE DI PELABUHAN KABIL PADA PT.PASADA ARTHA CARGO BATAM
}

\author{
${ }^{1}$ Suparman, ${ }^{2}$ Raiga Safira Aritonang \\ ${ }^{1,2}$ KPNK, Politeknik Adiguna Maritim Medan \\ Email : suparman29okt@gmail.com
}

\begin{abstract}
Abstrak. Proses Bongkar Muatan curah cair di pelabuhan Batam ini bertujuan mengenai Peran Perusahaan Bongkar Muat (PBM) dalam Proses Bongkar Muatan Kapal Asing di pelabuhan Kabil pada PT. Pasada Artha Cargo Batam. Proses penanganan Bongkar Muat dan persiapan penyediaan dokumen bongkar muat kapal serta kegiatan instansi yang berhubungan dengan kegiatan bongkar muat kapal di pelabuhan Batam. Dengan adanya hubungan yang baik dengan instansi pemerintah di pelabuhan maupun pemilik barang (owner) yang dilakukan oleh PT. Pasada Artha Cargo Batam merupakan salah satu kelancaran kegiatan bongkar muat yang dilakukan PT. Pasada Artha Cargo Batam. Sehingga perusahaan leluasa menyampaikan informasi baik itu tentang kegiatan bongkar muat, kebutuhan bongkar muat, dan lainnya. Kegiatan ini sangat membatu dalam kegiatan Ekspor dan Impor barang muatan yang di angkut oleh kapal. Oleh karana itu Perusahaan Bongkar Muat PT. Pasada Artha Cargo Batam sangat berusaha melakukan pelayanan baik agar dapat berjalan lancar sehingga tidak menghambat proses kegitan Bongkar Muat kapal. Hal tersebut akan berjalan lancar apabila karyawan perusahaan bekerja sangat teliti agar dokumen sesuai dengan prosedur yang ada di wilayah pelabuhan Batam. Salah satu bentuk contoh dokumen seperti Manisfest inward dan Manifest Outward akan di ajukan kepada kantor Bea dan Cukai agar kegiatan bisa segera dapat di proses. Alasan saya memilih judul makalah tentang "Proses Bongkar Muatan Curah Cair Dari Kapal MT. SUNRISE HOPE Di Pelabuhan Kabil Pada PT. Pasada Artha Cargo Batam" merupakah salah satu upaya agar bisa memberitahu kepada pembaca yang akan membaca makalah ini dan bisa memberikan sedikit ilmu tentang proses bongkar muat pada kapal curah cair. Berdasarkan pengamatan pada waktu Praktek Darat (PRADA) penulis melakukan dengan menggunakan data Field Research dan Library Reseacrh.
\end{abstract}

Kata Kunci: Bongkar Muat,Curah Cair, MT. Sunrise Hope,PT.Pasada Artha Cargo Batam

\begin{abstract}
This liquid bulk unloading process at the Batam port aims at the Role of the Unloading Company (PBM) in the Unloading Process of Foreign Ships at the Kabil port at PT. Pasada Artha Cargo Batam. The process of handling loading and unloading and preparing for the provision of documents for loading and unloading ships as well as agency activities related to loading and unloading activities at the port of Batam. With a good relationship with government agencies at the port and the owner of the goods (owner) carried out by PT. Pasada Artha Cargo Batam is one of the smooth loading and unloading activities carried out by PT. Pasada Artha Cargo Batam. So that the company is free to convey information both about loading and unloading activities, loading and unloading needs, and others. This
\end{abstract}


activity is very helpful in the export and import of cargo carried by ships. Therefore, the loading and unloading company PT. Pasada Artha Cargo Batam is trying very hard to provide good service so that it can run smoothly so as not to hamper the process of loading and unloading ships. This will run smoothly if the company's employees work very carefully so that the documents comply with existing procedures in the Batam port area. One form of sample documents such as Manisfest Inward and Manifest Outward will be submitted to the Customs and Excise office so that activities can be processed immediately. The reason I chose the title of the paper is "The Process of Unloading Liquid Bulk From MT Ships. SUNRISE HOPE At Kabil Port At PT. Pasada Artha Cargo Batam" is an effort to inform readers who will read this paper and can provide a little knowledge about the loading and unloading process on liquid bulk vessels. Based on observations at the time of Land Practice (PRADA), the author uses Field Research and Library Research data.

Keywords: Loading and Unloading, Liquid Bulk, MT. Sunrise Hope, PT. Pasada Artha Cargo Batam

\section{PENDAHULUAN}

Pelabuhan adalah tempat yang terdiri dari daratan dan perairan di sekitarnya dengan batas-batas tertentu sebagai tempat kegiatan pemerintah dan kegiatan ekonomi yang dipergunakan sebagai tempat kapal bersandar, berlabuh, naik turun penumpang dan bongkar muat barang yang dilengkapi fasilitas keselamatan pelayaran dan kegiatan penunjang pelabuhan, serta sebagai tempat transportasi. Pelabuhan juga merupakan pintu suatu negara bagi keluar masuknya berbagai arus barang ekspor dan impor.

Berdasarkan kegiatan usaha jasa di pelabuhan sebagai penunjang kegiatan angkutan laut salah satunya yaitu kegiatan bongkar muat barang. "Menurut Pasal 1 ayat 14 Peraturan Pemerintah Republik Indonesia No. 20 Tahun 2010 Tentang Angkutan Di Perairan, kegiatan bongkar muat barang adalah kegiatan usaha yang bergerak dalam bidang bongkar dan muat barang dari dan ke kapal di pelabuhan yang meliputi kegiatan stevedoring, cargodoring, dan receiving/delivery. Kegiatan bongkar muat ini merupakan salah satu mata rantai dari kegiatan pengangkutan barang melalui laut, dimana barang yang akan diangkut dari kapal melalui pipa yang berada di pelabuhan". http//jdih.dephub.go.id

Maju atau mundur sebuah pelabuhan laut dalam menunjang pertumbuhan ekonomi sangat tergantung pada kesiapan kegiatan curah cair tersebut, volume kunjungan kapal, baik kapal Tanker dan kapal cargo serta fasilitas pelabuhan yang memadai untuk mendorong kegiatan bongkar muat barang dari/dan ke kapal merupakan komoditi yang laku dijual baik di pasar dalam negeri dan di luar negeri. Produktivitas pelabuhan Kabil Batam meningkat kegiatan bongkar atau muat Crude Palm Oil yang tidak lepas dari kesiapan dan profesionalisme Perusahaan Bongkar Muat PT. Pasada Artha Cargo Batam.

Kegiatan bongkar muat di pelabuhan Kabil Batam dibidang penyediaan dan pelayanan jasa dermaga untuk kegiatan bongkar muat curah cair pelabuhan menyediakan peralatan alat-alat bongkar, pelayanan jasa terminal, dan pelayanan jasa bongkar kegiatan.

Setiap usaha pasti memiliki resiko dan tanggung jawab dalam pelaksanaannya, begitu pula dengan perusahaan bongkar muat barang angkutan laut yang memiliki resiko yang tinggi dalam kegiatan pelaksanaan kegiatannya. Dalam praktek dilapangan permasalahan dalam proses bongkar muat masi sering terjadi dan menimbulkan kerugian yang tidak sedikit. Contoh seperti pemilik barang tidak mau terima dengan kejadian yang terjadi dilapangan sehinggaa pemilik barang tidak mau claim kerusakan yang terjadi.

Terkait pembahasan yang dibahas tentang proses bongkar muatan curah cair. Curah cair adalah sebuah jenis barangan berupa cairan liquid seperti minyak kelapa sawit, minyak mentah, bahan kimia dan lain-lain.

Berdasarkan uraian diatas, maka penulis membahas pokok permasalahan pada bidang kegiatan 
bongkar muat kapal asing dalam bentuk sebuah Makalah dengan judul: "Proses Bongkar Muatan Curah Cair Dari Kapal MT. Sunrise Hope Di Pelabuhan Kabil Pada PT. Pasada Artha Cargo Batam".

\section{METODE PENELITIAN}

Dalam memperoleh data yang dibutuhkan sebagai bahan penyusunan makalah, penulis menggunakan metode yang digunakan penulis dalam penulisan makalah ini adalah sebagai berikut:

1).Data lapangan (Field Research)

a).Melakukan pengamatan (observation) : Dalam metode ini penulis secara langsung mengamati kegiatan proses bongkar muatan di PT. Pasada Artha Cargo Batam.

b).Melakukan Wawancara (interview): Wawancara ini merupakan teknik pengumpulan data tanya jawab penelitian langsung secara lisan untuk mendapatkan informasi dan keterangan dari senior dan karyawan yang berkerja di PT. Pasada Artha Cargo Batam.

\section{2).Data perpustakaan (Library Research)}

Metode yang digunakan untuk memperoleh dan mengumpulkan data dari literature karya - karya ilmiah maupun dari catatan - catatan kuliah yang berhubungan dengan isi makalah. Dalam hal ini penulis secara langsung berkunjung ke perpustakaan yang berada di Kota Medan dan perpustakaan Kampus Poltek Ami Medan untuk memperoleh beberapa data yang diperlukan untuk kesempurnaan makalah ini.

\section{HASIL DAN PEMBAHASAN}

\section{A.Sejarah Singkat Perusahaan}

PT. Pasada Artha Cargo Batam di dirikan pada tahun 2002 yang beralamat di Komplek Stevonica No. 05 Jalan Gajah Mada Tiban III kelurahan Lestari Kecamatan Sekupang Batam oleh Ibu Louis Margartha Sroyer dan menjabat sebagai Direktur dan pemilik perusahaan dengan kegiatan pokok usaha Bongkar Muat.

Seiring berjalannya waktu perkembangan perusahaan PT. Pasada Artha Cargo Batam semakin membaik dalam melayani bongkar muatan kapal dalam maupun luar negri untuk barang khusus. Sudah berjalan selama 18 tahun yang terhitung dari tahun 2002 sampai dengan sekarang.
Pada awal tahun 2017 PT. Pasada Artha Cargo Batam meresmikan serah terima perusahaan yang dimana sebelumnya dipimpin oleh Ibu Louis Margartha Sroyer berpindah ke Bapak Yudhadi Brata Putra yaitu anak pertama dari ibu Louis dan Bapak Efendi Saragih selaku salah satu alumni di Akademi Maritime Indonesia Medan.

Tahun 2017 juga PT. Pasada Artha Cargo Batam berpindah alamat di Kompleks Perumahan Dutamas Blok-B No.17 Kecamatan Batam Centre dan meresmikan pembukaan perusahaan barunya di bagian keagenan yang disebut PT. Sarana Trans Asia Batam perusahaan bergerak di bidang clearence in/out, crewing, dan melayani kebutuhan kapal lain. Perusahaan PT. Sarana Trans Asia Batam ini dimiliki oleh Ibu Louis Margartha Sroyer.

\section{B. Instansi Yang Terkait dalam Proses Bongkar Muatan Curah Cair}

Dalam prosedur pembongkaran pihak Perusahaan Bongkar Muat (PBM) juga berkaitan dengan instansi pemerintah seperti Syahbandar dan BP Batam dalam pengurusan bongkar muat. Seperti mendaftarkan nama kapal, jumlah muatan, nama muatan, bayar biaya dermaga dan jumlah perpindahan saat pembongkaran.

\section{C.Proses Pengurusan Dokumen Bongkar Muat}

Dalam kegiatan Bongkaran muat pihak Perusahaan Bongkar Muat (PBM) harus mempersiapkan untuk melakukan kegiatan bongkar. Yang harus di persiapkan oleh pihak Perusahaan Bongkar Muat (PBM) ialah:

a).From Ceklis

Sebelum melakukan pengimputan data dan kagiatan kapal di Pusat Pelayanan Administrasi Terpadu (PPAT) pihak Perusahaan Bongkar Muat (PBM) melakukan from ceklis, dimana isi from ceklis tersebut berisi jenis kegiatan bongkar muat dan berupa jenis pemilihan bank untuk transaksi pembayaran kegiatan bongkar muat.

\section{b).Pusat Pelayanan Administrasi Terpadu (PPAT)}

Setelah melakukan from ceklis pihak Perusahaan Bongkar Muat (PBM) melakukan antrian di Pusat Pelayanan Administrasi Terpadu (PPAT) karena setiap agen dan perusahaan bongkar muat yang berada di kawasan Batam wajib melakukan imput dokumen kegiatan di Pusat Pelayanan Administrasi Terpadu (PPAT) dan setalah melakukan pengimputan dokumun oleh sistem Bp Batam pihak 
Perusahaan bongkar muat meneruskan berkas kepada Verifikasi.

Dokumen yang diperlukan saat melampirkan di Pusat Pelayanan Administrasi Terpadu (PPAT) :

1).Lampiran from ceklis, yang berisi Nama Kapal, Tempat kegiatan, Jenis kegiatan kapal, jadwal kegiatan dan nama agen kapal.

2).Lampiran 1b, yang berisi Nama kapal, Tempat kegiatan, jenis kegiatan, Nama agen kapal, Nomor Penunjukan Urut Kapal (Nomor PUK) dan lampiran manifest.

\section{c).Verifikasi}

1).Verifikasi oleh Kapala Seksi

2).Verifikasi oleh kepala Bidang

Setelah melakukan pengecekan data kegiatan bongkar muat Kepala Seksi dan Kepala bidang, pihak Perusahaan Bongkar Muat (PBM) melanjutkan data kegiatan ke bagian Hold Dana.

Dokumen yang dilampiran pada saat kegiatan verifikasi :
a).Lampiran from ceklis
b).Lampiran 1b
c).Lampiran Manifes

Sama seperti lampiran yang di ajukan di Pusat Pelayanan Administrasi Terpadu (PPAT) akan tetapi ketiga lampiran tersebut harus sudah terimput data oleh Sistem Pusat Pelayanan Administrasi Terpadu (PPAT) agar kegiatan Verifikasi bisa di lakukan.

\section{d).Hold Dana}

Hold Dana adalah dimana dana yang tertertahan/dana yang dibekukan untuk suatu jenis kegiatan bongkar muat melalui House To House dari bank perusahaan bongkar muat (PBM) ke bank BP Laut Batam dan pembayaran memiliki sistem auto debit. Setelah melakukan Hold dana atau melakukan pembayaran tarif hold dana sesuai jenis kegiatan pihak Perusahaan Bongkar Muat (PBM) melanjutkan kegiatan proses Realisasi Satuan Kerja (SATKER).

Dokumen yang di perlukan saat kegiatan Hold dana ialah dokumen yang disetujui oleh Verifikasi yang telah dinaikkan kepada Kepala Seksi dan Kepala Bidang Badan Pelabuhan Batam (BP Batam) dan akan di ajukan ke kegiatan Hold dana. Apabila dana yang sudah dibekukan maka dokumen Hold dana akan keluar dan akan bisa langsung melakukan kegiatan Realisasi Satuan Kerja (SATKER).

\section{e). Realisa Satuan Kerja (satker)}

Realisasi adalah suatu jenis kegiatan yang benar-benar terjadi/real di lapangan. Contoh kegiatan nya dimana pembayaran awal atau pembayaran di Hold Dana 2000 MT dan ternyatan pembayaran di lapangan sejumlah 2200 MT maka pihak Perusahaan Bongkar Muat membayar sesuai kegiatan yang terjadi dilapangan. Dan setelah melakukan kegiatan dilapangan pihak Perusahaan Bongkar Muat (PBM) melakukan Verivikasi kembali pada Kepala Seksi dan Kepala Bidang Bp Batam untuk mendapatkan Vaktur lunas.

Dokumen yang di perlukan saat Realisasi adalah semua dokumen yang telah di selesai pada saat kegiatan From Ceklis, Imput PPAT, Verifikasi, dan Hold Dana. Semua dokumen akan di lampirkan dan Realisai Satuan Kerja (SATKER) untuk kegiatan Real/terjadi dilapangan Pihak Perusahaan Bongkar Muat (PBM) harus melunaskan tarif Bongkar Muat agar kegiatan realisasi dapat dilanjutkan ke Vaktur Pelunasan

\section{f). Vaktur Lunas \\ Vaktur Lunas adalah biaya tagihan yang sebenarnya terjadi dilapangan.}

\section{D).Pelayanan Muatan Curah Cair}

Muatan curah cair dan bongkar dialirkan melaluisaluran pipa (pipeline) dengan tenaga pompa. Instalasi pipa menghubungkan ruang muatan di kapal dengan tanki simpan di darat, atau sebaliknya dari tangki timbun di darat kapal. Pompa, motor listrik, keran-keran (valves), dan jaringan pipa berfungsi sebagai alat utama bongkar muatan. Kegiatan bongkar muat barang curah kering/cair diselenggarakan di terminal serbaguna (multipurpose terminal) atau diterminal khusus curah yang dilengkapi dengan fasilitas dan intalasi khusus. Output bongkar muat sangat bergantung pada kapasitas alat atau mekanis terpasang.

\section{E).Peralatan Pokok Bongkar Muat Curah Cair}

Peralatan pokok untuk memindahkan muatan curah cair terdiri dari rangkaian alat yang membantu suatu system. Secara individual alat-alat tersebut tidak berdiri sendiri, melainkan satu persatu subsistem dari system bongkar muat secara keseluruhan. Muatan cair mengalir dari tangki timbun ke tanki kapal, dalam hal ini dari tanki kapal ke tanki timbun darat atau sebaliknya, dan atau dari mobil 
tanki angkutan jalan raya. Subsistem utama adalah pompa dan pipa fitting.

Pompa muatan curah yang banyak dipakai dikapal ialah dari jenis centrifugal pupm tipe singel atau multi stange. Kapasitas pompa dikapal mencapai $600 \mathrm{~m} / \mathrm{jam}$ atau lebih pada ketinggian head 80-90 meter. Head dan kapasitas ditentukan viskositas dan berat jenis muatan, dan panjang pipa tekanan.

\section{1).Tangki Timbun}

Tangki Timbun muatan curah cair tertutup sebagaimana pada gambar dihalamat berikut. Kontruksi curah cair semuanya berupa minyak, baik bahan pangan maupun non pangan terdiri dari pipa baja, fitting, valvet,dan tangki dari baja. Valvet berfungsi untuk alat kendal isi tangki ketika sedang dimuat dan dibongkar.

Pengawasan isi tangki dilakukan dengan alat sounding berupa seperangkat floater alat ukur elektronik yang berada di control room. Tangki curah cair dibangun dengan dinding berlapis antara kedua dinding lazinmnya diisi air yang berguna sebagai lapisan pengaman, sekalipun media memanaskan isi tangki terutama minyak berat.

\section{2).Stowage Factor Muatan Curah Cair}

Seperti halnya muatan curah kering untuk merencanakan ruang muatan cura cair diperlukan juga data besarnya ruang ditempati oleh satu ton muatan curah cair yang dimaksud barang jenis dari bahan cair merupakan penentu besarnya ruang per ton muatan. Minyak yang berat menempati ruang yang lebih sedikit dibandingkan minyak yang berat jenisnya lebih kecil.

\section{3).Output Bongkar Muat}

Untuk membongkar muatannya, dikapal tenker tersedia pompa berkekuatan besar agar waktu bongkar tidak terlalu lama sehingga dengan demikian waktu kapal ditambatkan, dan waktu kapal di pelabuhan menjadi singkat. Tanker yang besar dan tanker yang sangat besar membongkar muatan dengan tanpa terhambat di suatu pelabuhan, melaikan dari kapal ke kapal bahkan langsung sambil berlayar.

\section{F.Dokumen-dokumen Yang Diperlukan Saat Bongkar}

Untuk prosedur pelayanan kegiatan bongkar kapal asing ada beberapa dokumen yang diperlukan : 1).Penunjukan Surat PBM.

Ialah surat yang diberikan dari pihak perusahaan keagenan kapal kepada perusahaan bongkar muat untuk melakukan kegiatan bongkar muat pada kapal yang ingin melakukan kegiatan. Isi surat PBM ialah Nama kapal, Bendera/IMO Kapal, G.R.T, Panjang kapal/L.O.A, Rencana Bongkar atau
Muat, Pelabuhan tujuan dan Shipping atau Consignee.

2)Surat penunjukan kerja (SPK).

Ialah surat yang berisi tentang penyampaian laporan rencana pelaksanaan bongkar muat barang pada kantor pelabuhan paling lama satu hari sebelum kapal tiba di pelabuhan.

3).Packing list.

Ialah dokumen yang berisi rincian spesifikasi barang ekspor yang sesuai dengan invoice. Packing List dibuat oleh eksportir atau perusahaan yang melakukan pengemasan langsung terhadap barang tersebut. Pangking List befungsi untuk memudahkan dan mengetahui isi barang dalam kontainer apabila ada pemeriksaan.

4).Manifest.

Ialah keterangan rinci mengenai barang-barang yang diangkut oleh kapal jadi semua Bill Of Lading dari barang-barang yang diangkut kapal dan dijabarkan secara rinci.

5).Bill Of Lading

Ialah dokumen yang paling penting yang berlaku dalam kegiatan pengiriman barang domestik maupun ekspor dan impor.

6).Ship Particular

Ialah rincian data kapal lengkap sebagai identitas kapal termasuk General data, Machinary data, Hull data, Owner dan lain-lain.

\section{G.Hambatan Yang Dihadapi Saat Proses Bongkar}

1). Cuaca Buruk, dalam proses bongkar Crude Plam Oil cuaca sangat berpengaruh terhadap kegiatan pemuatan. Karena apabila cuaca hujan, kegiatan tidak dapat dilakukan. Kegiatan hanya bisa dilakukan pada saat cuaca cerah. Keadaan ini bukan kendala yang disebabkan langsung dari manusia itu sendiri.

2).Rusak peralatan ketika kegiatan bongkar berlangsung adanya kerusakan alat-alat seperti selang pipa dan lain-lain. Rusaknya peralatan bisa terjadi kapan saja dan dapat menghentikan proses pembongkaran.

3).Lamanya diterima dokumen pemuatan yang dikirim oleh agen pusat / general agent, hal ini akan mengakibatkan lama nya proses pemuatan di dermaga.

4).Jauhnya jarak temput pengurusan ke Instansiintansi terkait.

5).Sistem Pelayanan yang masih Manual.

\section{KESIMPULAN}

Berdasarkan uraian dari hasil pembahasan makalah diatas, Proses Bongkaran Muatan Curah 
Cair Kapal Mt. Sunrise Hope Di Pelabuhan Kabil Pada PT. Pasada Artha Cargo Batam telah berjalan dengan baik.dengan Standar Operasional yang telah ditentukan.

\section{DAFTAR PUSTAKA}

D.A Lasse, Manajemen Kepelabuhan, Jakarta: PT. Raja Grafindo Persada, 2016.

Inpres No.4/1985 jo, S.K.Menteri Perhubungan No.A1/300 No.A88 Tentang Bongkar Muat.

Isharyadi, Fenrian. Karakterisasi Fisikokimia Crude Plam Oil (CPO) di Daerah Sumatra dan Non Sumatra : Indonesia DSpace Grub, 2019. Sumber https://repository.ipb.ac.id/handle/1234 56789/100735 .

Kamus Besar Bahasa Indonesia, Semarang : Widya Karya, 2016

https://id.m.wikipedia.org/wiki/Proses.

Peraturan Menteri Perhubungan Republik Indonesia Nomor : PM 23 Tahun 2015

Tentang Peningkatan Fungsi

Penyelenggara Pelabuhan Pada

Pelabuhan Yang Di Usahakan Secara

Komersial. 